\title{
Evaluation of the Efficacy of 1940-nm Diode Laser in Tonsillectomy: Preliminary Report
}

\author{
Doh Young Lee \\ Jae-Gu Cho \\ $\mathrm{Nu}$-Ri Im \\ Hyun-Ji Lee \\ Byoungjae Kim \\ Kwang-Yoon Jung \\ Tae Hoon Kim \\ Seung-Kuk Baek
}

Department of Otorhinolaryngology-Head and Neck Surgery, Korea University College of Medicine, Seoul, Korea
Received May 22, 2015

Revised June 1, 2015

Accepted June 5, 2015

\footnotetext{
Correspondence

Seung-Kuk Baek

Department of Otorhinolaryngology-Head and Neck Surgery, Korea Univsersity Anam Hospital, 73 Inchon-ro, Seongbuk-gu, Seoul 136-705, Korea Tel: +82-2-920-6618

Fax: +82-2-920-5233

E-mail: mdskbaek@gmail.com

(c) Korean Society for Laser Medicine and Surgery

@C This is an open access article distributed under the terms of the Creative Commons Attribution NonCommercial License (http://creativecommons.org/ licenses/by-nc/4.0) which permits unrestricted noncommercial use, distribution, and reproduction in any medium, provided the original work is properly cited.
}

\author{
Background and Objectives \\ The aim of this clinical feasibility study was to assess preliminary results \\ regarding postoperative outcomes of tonsillectomy using a laser system \\ emitting at $1940 \mathrm{~nm}$.
}

\section{Materials and Methods}

This clinical feasibility trial included six patients suffering from chronic tonsillitis. Tonsillectomy was performed using a $1940 \mathrm{~nm}$ laser with $6 \mathrm{~W}$ of output power. Intraoperative scoring was performed by a surgeon rating the cutting capacity of the device (5 point scale, 1-5), as well as intraoperative bleeding (3 point scale, 0-2). Patient surveys of pain and the surgeon's reports on postoperative changes in the surgical field (11 point scale, 0-10) were also analyzed on postoperative day one, and after week(s) one and two.

\section{Results}

No complications were observed in patients. The surgeon's mean rating on the cutting capacity of the laser was $4.33 \pm 1.96$. Bleeding was almost absent, with a mean blood loss of $2.3 \mathrm{ml}$. Postoperative pain abruptly decreased after postoperative week one $(4.83 \pm 2.23,3.33 \pm 2.65,1.17 \pm$ 0.75 at postoperative day one, week one, and week two, respectively), with a statistically significant difference observed between postoperative day one and week two $(p=0.008)$. Two patients required additional pain relief for five days after postoperative week one. Swelling had decreased significantly by postoperative week one $(p=0.004)$, with a score of nearly 0 by postoperative week two. The mean scores for changes in scarring were $4.83 \pm 0.40,2.83 \pm 1.21$, and $1.67 \pm 2.07$ at postoperative day one, week one, and week two.

\section{Conclusion}

A $1940 \mathrm{~nm}$ laser demonstrated excellent intraoperative performances and postoperative outcomes in tonsillectomy. In addition, conduct of more large-scale and comparative studies is warranted in order to elucidate the efficacy of this laser treatment for tonsillectomy.

\section{Key words \\ 1940-nm; Laser; Tonsillectomy; Pain; Bleeding}




\section{INTRODUCTION}

Tonsillectomy is one of the most frequently performed operations in the otolaryngology field, with postoperative pain and bleeding the most common complications for patients who undergo this procedure. Several approaches have been used to solve such problems. For instance, in terms of new surgical approaches, various novel techniques and instruments have been introduced: cold instruments, and monopolar and bipolar electrocautery are now widely used in tonsillectomies. Recently, ultrasonic instruments such as the Harmonic scalpel and Coblator have also been introduced. ${ }^{1-3}$ Since, these ultrasonic instruments are operated at lower temperatures $\left(60-100^{\circ} \mathrm{C}\right)$ than conventional bipolar electrocautery $\left(150-400^{\circ} \mathrm{C}\right)$, it is thought that postoperative pain is likely reduced. ${ }^{4}$ However, the efficacy of ultrasonic devices for tonsillectomy is still debatable, although those devices have been reported to induce fewer complications if the expert surgeon uses such instruments with appropriate caution. ${ }^{5}$

Lasers have been widely used for intraoral soft tissue procedures and transoral endolaryngeal operations. They can be used to produce immediate and precise tissue destruction in a bloodless manner, forming an incision or ablation with minimal thermal damage to the surrounding, healthy tissue. ${ }^{6}$ Such properties allow lasers to be used with ease in the surgical treatment of vascular lesions, while rendering pharmacological therapy unnecessary for patients with coagulation problems. Moreover, the incisions are self-sterilizing and are formed with minimal tissue distortion while the sealing ability of the laser provides a bloodless dissection. Small blood vessels (up to $0.5 \mathrm{~mm}$ in diameter), lymphatic vessels, and nerve endings are sealed by the beam, which thus provides hemostasis, and contributes to a lack of intraoperative and postoperative pain. Herein, we aimed to evaluate the efficacy of a specific type of laser, using a $1940 \mathrm{~nm}$ wavelength, in tonsillectomy and to report our preliminary results.

\section{MATERIALS AND METHODS}

\section{Patients}

From April to May 2015, this study prospectively enrolled six patients who underwent tonsillectomy, performed with a $1940 \mathrm{~nm}$ laser. All patients were diagnosed with chronic tonsillitis and followed up for two weeks after tonsillectomy. Patients under 20 years of age and with inadequate follow-up were excluded. This study was approved by the Institutional Review Board of Korea University Hospital (IRB No. MD15001).

\section{Laser system}

A laser system (Xlender-Y; Wontech, Daejeon, South Koreal emitting a wavelength of $1940 \mathrm{~nm}$ was used for the operation (Fig. 1). The output of a laser diode module is coupled into an optical fiber in order to deliver light to the location of the operation. The fiber-coupled diode module offers up to $12 \mathrm{~W}$ of output through a $600 \mu \mathrm{m}$ diameter optical fiber with a 0.22 numerical aperture. The output power and exposure time of the laser were accessed via a user interface to set parameters.

\section{Procedure}

The operation was performed by a single surgeon (SK Baek). Patients were placed in a supine position under general anesthesia, and a Dingman mouth gag was applied to open each patient's mouth. The mode of the laser was set to 6 watt of power, 1,000 Hz, and $70 \%$. An incision was made into the anterior pillae of the tonsil (Fig. 2A, 2B), and the tonsil capsule identified (Fig. 2C). A plane between the tonsil capsule and adjacent muscle was dissected using the laser (Fig. 2D, 2E), with the level

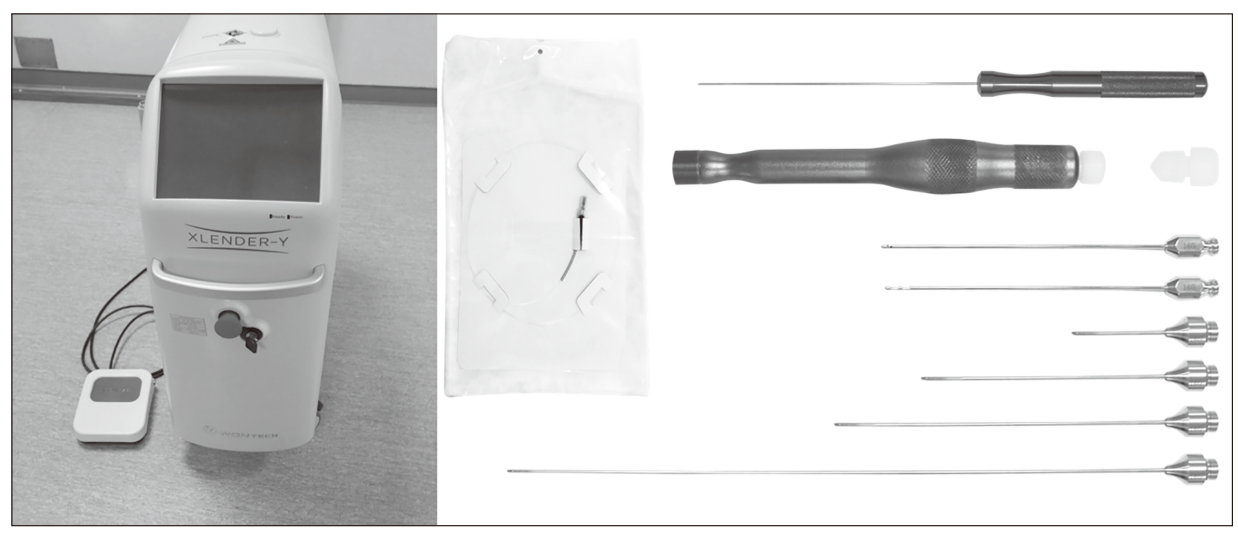

Fig. 1. Laser system. The laser system (Xlender-Y; Wontech, Korea) emitting at a wavelength of $1940 \mathrm{~nm}$. 

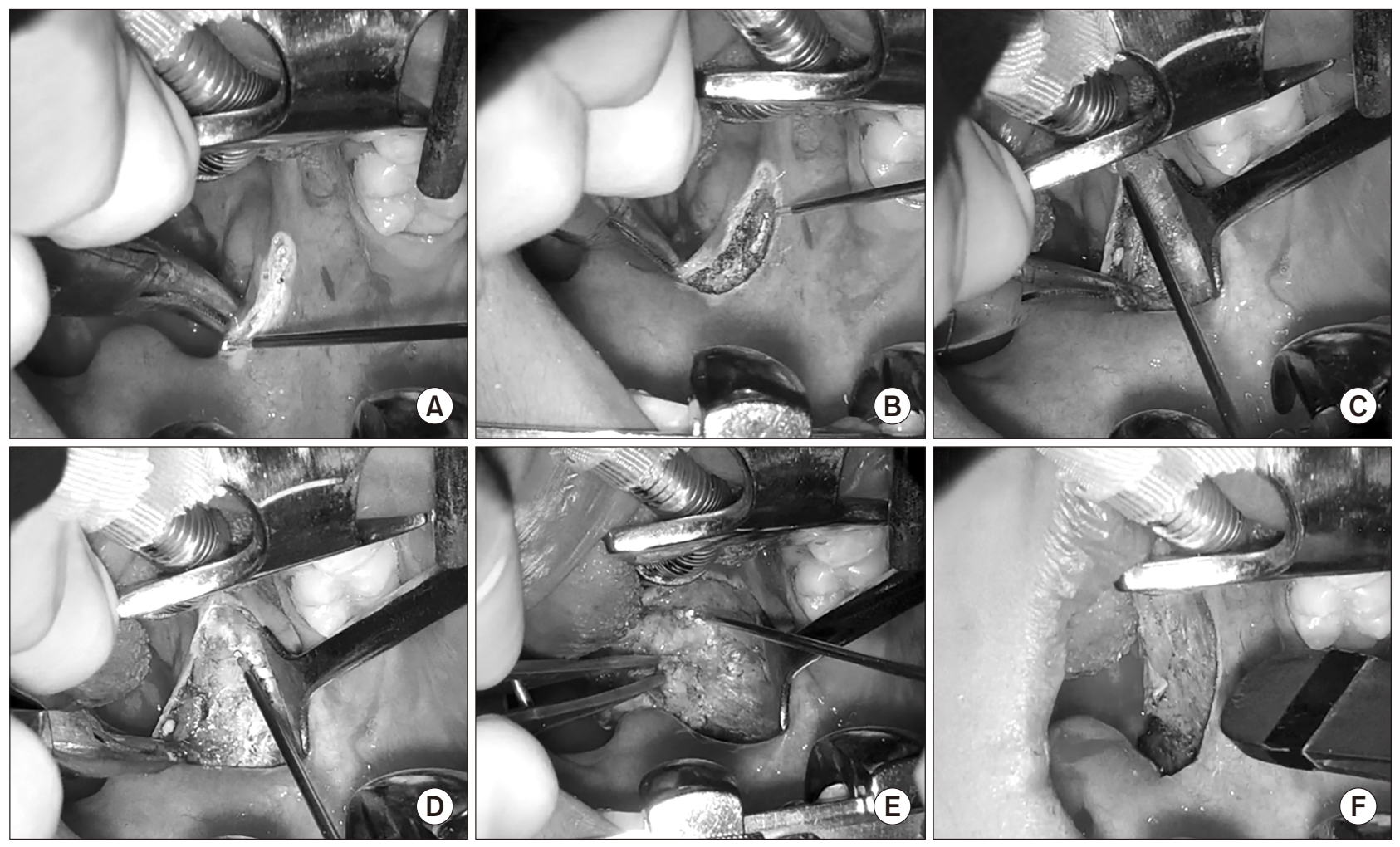

Fig. 2. Operation. (A, B) Incision on the anterior pillae of tonsil, (C) Identification of the capsule of tonsil, (D, E) Dissection of the plane between the capsule of tonsil and adjacent muscle, (F) Surgical bed after finishing the operation.

of defocusing used based on the surgeon's experience. When mild bleeding occurred, the laser was set to a defaced mode to control this. However, in the case of moderate bleeding, when the laser could not effectively stop bleeding, bipolar electrocauterization was used for better control. After extracting the tonsils, the surgical bed was re-evaluated (Fig. 2F), and further control of bleeding was performed, if necessary.

\section{Clinical parameters}

The efficacy of the $1940 \mathrm{~nm}$ laser was evaluated by the surgeon's rating of the cutting capacity of the device, as well as of any intraoperative bleeding. A 5 point grading scale was used for cutting capacity, where $1=$ insufficient, 2 = poor, 3 = moderate, 4 = good, and $5=$ very good. For bleeding, a 3 point grading scale was used, where 0 $=$ no bleeding, 1 = mild bleeding without requiring the additional application of a laser for bleeding control, and 2 = bleeding requiring additional procedures. The number of times electrocauterization was used for the control of bleeding during an operation was also analyzed. Postoperatively, by day one, week one, and week two, the surgeon's ratings of swelling, scar contraction, and bleeding were analyzed using a 10 point grading scale. In the same period, patients' reports on pain using a 10 point scale, and any additional days requiring pain relief after postoperative week one, were also evaluated.

\section{RESULTS}

This study included three males and three females, with a median age of 26.2 years (20-45). The diagnosis for all patients was chronic tonsillitis, with throat pain and fever recurring greater than four times per year over a five-year period. The mean operation time was $22.8 \pm 5.8$ minutes. All patients were discharged on postoperative day one without any complications, and without any postoperative bleeding or re-admission during the postoperative two weeks after discharge.

Table 1 summarizes intraoperative findings for each patient. The mean score for the surgeon's rating of the cutting capacity of the laser was $4.33 \pm 1.96$. Among the six patients, intraoperative bleeding was rated 0 in four patients and 1 in two patients. Bleeding was almost absent, with a mean $2.3 \mathrm{ml}$ of blood lost. The number of patients using bipolar electrocauterization was less than two in four.

Postoperative pain abruptly decreased after one week 
Table 1. Demographics and intraoperative findings

\begin{tabular}{cccccccc}
\hline No. & Age & Sex & Operation time $(\mathrm{min})$ & Cutting capacity* & Intraoperative bleeding ${ }^{\dagger}$ & Amount of bleeding (ml) & $\begin{array}{c}\text { Number of bipolar } \\
\text { electrocauterization }\end{array}$ \\
\hline 1 & 27 & Female & 15 & 4 & 0 & 0 & 0 \\
2 & 24 & Male & 25 & 4 & 0 & 5 & 2 \\
3 & 20 & Male & 25 & 5 & 1 & 2 & 4 \\
4 & 45 & Female & 20 & 5 & 0 & 1 & 1 \\
5 & 20 & Female & 20 & 5 & 0 & 5 & 1 \\
6 & 21 & Male & 32 & 3 & 1 & 5 \\
\hline
\end{tabular}

*1 $=$ insufficient, 2 = poor, $3=$ moderate, $4=$ good, $5=$ very good.

$\dagger_{0}=$ no bleeding, 1 = mild bleeding without requiring additional appliance of laser for bleeding control, $2=$ bleeding requiring additional procedure.

A

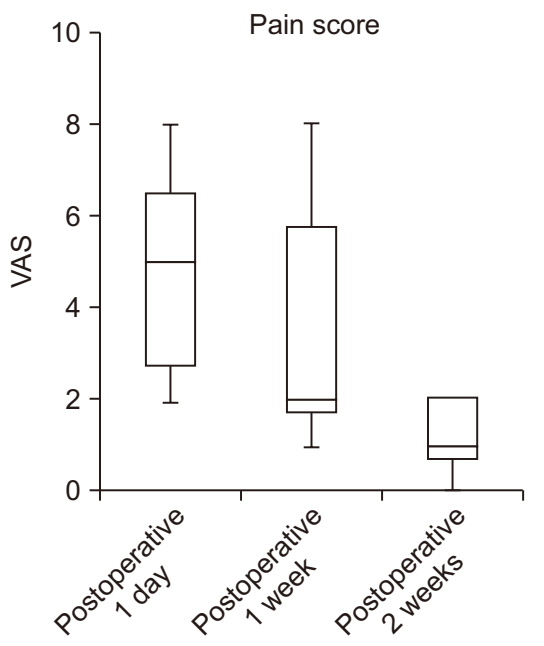

B

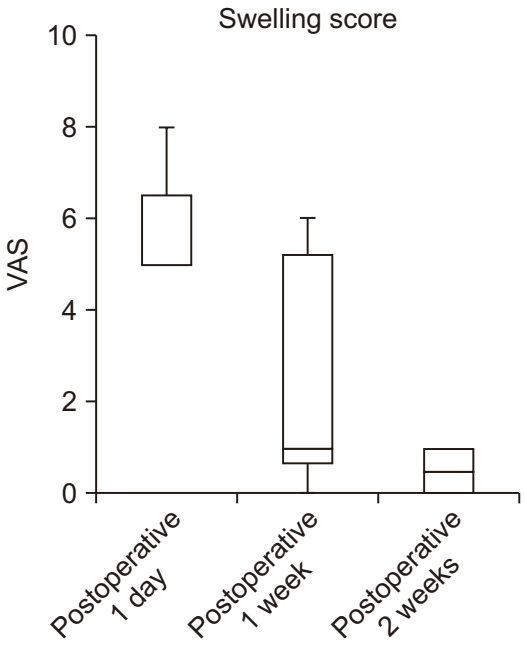

C

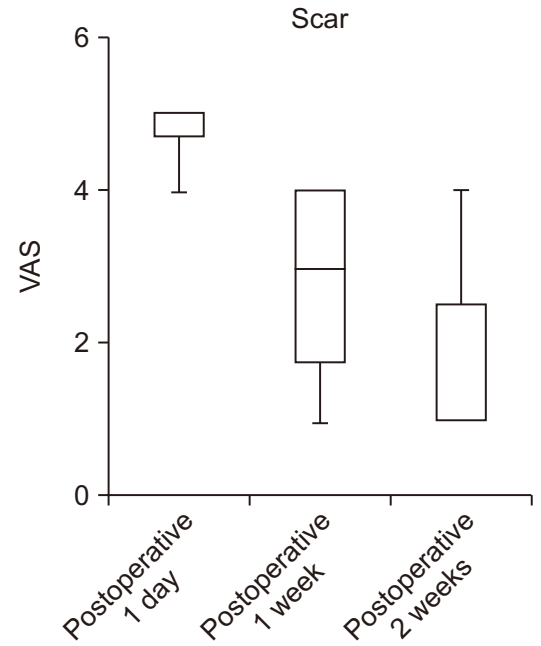

Fig. 3. Postoperative change of pain (A), swelling (B), and scarric change (C).

$(4.83 \pm 2.23,3.33 \pm 2.65,1.17 \pm 0.75$ at postoperative day one, week one, and week two, respectively), with a statistically significant difference observed between postoperative day one and week two ( $p=0.008$; Fig. 3A). Two patients needed additional pain relief for five days after postoperative week one. Swelling significantly decreased by postoperative week one $(p=0.004)$, with a score of nearly 0 by postoperative week two (Fig. 3B). The mean scores for changes in scarring were $4.83 \pm 0.40,2.83$ \pm 1.21 , and $1.67 \pm 2.07$ by postoperative day one, week one, and week two, respectively (Fig. 3C).

\section{DISCUSSION}

This study demonstrates that tonsillectomy using a $1940 \mathrm{~nm}$ laser is feasible and shows excellent intraoperative performances and postoperative outcomes. The operating time using this technique was short, with the laser showing an acceptable cutting capacity. Pain was abruptly reduced at the postoperative week one mark, with no postoperative bleeding apparent. Fig. 4 shows the postoperative healing process, with the tonsil fossa previously covered by exudative mucosa at postoperative week one, which then became completely healed by postoperative week two.

Clinically, the thulium laser was first introduced to urology for prostate resectioning, ${ }^{7-9}$ and is currently under study for laparoscopic partial nephrectomies..$^{10-12}$ It has also been used in the areas of ophthalmology, ${ }^{13,14}$ and neurology. ${ }^{15}$ These studies characterized the device as a precise cutting tool causing well-defined thermal damage to ensure hemostasis. In otorhinolaryngology, several studies have shown the efficacy of a $1940 \mathrm{~nm}$ laser in various procedures specific to this field: ${ }^{16-18}$ Guney et al. reported on the ablation efficacy of a $1940 \mathrm{~nm}$ laser in intraoral surgery. ${ }^{6}$ Considering that the output wavelength 

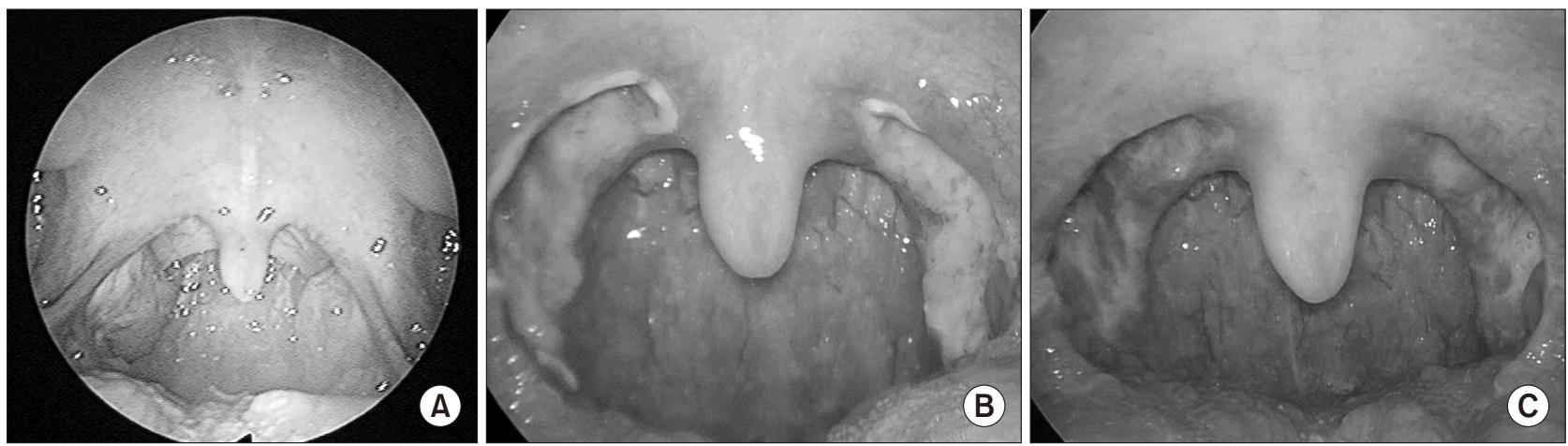

Fig. 4. Pre- and postoperative photo. (A) Preoperative, (B) Postoperative 1 week, (C) Postoperative 2 weeks.

of a $1940 \mathrm{~nm}$ laser coincides with water's absorption peak, a flexible application is possible with a fibertype laser; its clinical application could also be further widened, especially in the field of otorhinolaryngology with its evident anatomical complexities. Moreover, in regards to intraoral soft tissue operations, we believe that a 1940 $\mathrm{nm}$ laser is advantageous for the following reasons: 1) it is user-friendly, 2) has good cutting power, 3) induces relatively good coagulation, and 4) shows less collateral tissue damage.

Of the many different laser types that are currently used, $\mathrm{CO}_{2}(10,600 \mathrm{~nm})$, Er:YAG lerbium-doped yttrium aluminium garnet: $2940 \mathrm{~nm}$ ), and Er, Cr:YSGG (erbium, chromium-doped: yttrium, scandium, gallium, and garnet; $2780 \mathrm{~nm}$ ) lasers are of great interest due to their emission wavelengths being close to water absorption peaks. ${ }^{19}$ However, their wavelengths cannot be transmitted through silica fibers: $\mathrm{CO}_{2}$ lasers utilize articulated arms or special hollow waveguides, whereas Er:YAG requires fluoride glass or sapphire fibers. In contrast, a laser with a $1940 \mathrm{~nm}$ emission wavelength that overlaps with one of the water absorption peaks and that can be transmitted through silica fibers is a promising tool for intraoral surgery. Ronald et al. reported that treatment of hyperplastic inferior turbinates using a $1940 \mathrm{~nm}$ fiber laser provided sufficient tissue reduction in a relatively short operation time and used a low total energy. Such characteristics of the $1940 \mathrm{~nm}$ laser highlights its excellent cutting ability, and holds great promise for intraoral surgery, including tonsillectomy.

The thermal damage zone, which is formed by the deep penetration of a $1940 \mathrm{~nm}$ laser into tissue, is expected to provide good hemostatic capabilities, allowing the laser to be used quickly and safely on well-perfused tissues such as tonsils. ${ }^{b}$ Considering postoperative bleeding is a major concern after tonsillectomy and that its prevalence has ranged from $2.8 \%$ to $15.9 \%$ of patients, ${ }^{20,21}$ hemostatic potential is one of the most important factors in assessing the feasibility of surgical tools in this commonly performed procedure. Although patient numbers were small, our study demonstrated that patients did not show major postoperative bleeding.

Postoperative pain is another issue that tonsillectomy patients potentially face. A larger coagulation zone means more thermal damage to healthy tissue, which would make the application of this wavelength on delicate tissues unfeasible. However, the high absorption coefficient of a $1940 \mathrm{~nm}$ laser allows a shallow penetration depth, enabling precise ablation with less thermal damage. ${ }^{6}$ Our study showed pain decreased sharply after postoperative week one, which was comparable to other studies. ${ }^{22}$ Shallow ablations at low power may prove useful in operations in which only the outermost layers of tissue are affected, since this would minimize thermal damage to normal tissue and, presumably, also decrease postoperative pain.

Although our study had obvious limitations such as the number of patients being small, it is nevertheless valuable in that it is the first to evaluate the efficacy of a $1940 \mathrm{~nm}$ laser during tonsillectomy. We believe our results to be important and are a good basis for further comparable studies using larger cohorts. In conclusion, a 1940 nm laser, which shows excellent intraoperative performances and postoperative outcomes in tonsillectomy, requires further comparative studies to elucidate its efficacy in this common surgical procedure.

\section{ACKNOWLEDGMENTS}

This research was supported by the Korea Health Technology R\&D Project (grant number: HI14C0748) through the Korea Health Industry Development Institute 
(KHIDI) by the Ministry of Health \& Welfare, and a Grantin-Aid for Korea University Research and Business Foundation.

\section{REFERENCES}

1. Sharma A, Muna S, Fahmy FF. The ultrasonically activated scalpel versus bipolar diathermy for tonsillectomy: a prospective randomized trial. Clin Otolaryngol 2005;30:284; author reply 284-5.

2. Sheahan P, Miller I, Colreavy M, Sheahan JN, McShane D, Curran A. The ultrasonically activated scalpel versus bipolar diathermy for tonsillectomy: a prospective, randomized trial. Clin Otolaryngol Allied Sci 2004:29:530-4.

3. Parsons SP, Cordes SR, Comer B. Comparison of posttonsillectomy pain using the ultrasonic scalpel, coblator, and electrocautery. Otolaryngol Head Neck Surg 2006;134:10613.

4. Chang H, Hah JH. Comparison of post-tonsillectomy pain with two different types of bipolar forceps: low temperature quantum molecular resonance device versus high temperature conventional electrocautery. Acta Otolaryngol 2012;132 Suppl 1: S130-3.

5. Kim JW, Mun SJ, Lee WH, Mo JH. Post-tonsillectomy hemorrhage in children: a single surgeon's experience with coblation compared to diathermy. Eur Arch Otorhinolaryngol 2013;270:339-44.

6. Guney M, Tunc B, Gulsoy M. Investigating the ablation efficiency of a 1940-nm thulium fibre laser for intraoral surgery. Int J Oral Maxillofac Surg 2014;43:1015-21.

7. Bach T, Netsch C, Pohlmann L, Herrmann TR, Gross AJ. Thulium:YAG vapoenucleation in large volume prostates. J Urol 2011;186:2323-7.

8. Bach T, Xia SJ, Yang Y, Mattioli S, Watson GM, Gross AJ, et al. Thulium: YAG 2 mum cw laser prostatectomy: where do we stand? World J Urol 2010;28:163-8.

9. Bach T, Netsch C, Haecker A, Michel MS, Herrmann TR, Gross AJ. Thulium:YAG laser enucleation (VapoEnucleation) of the prostate: safety and durability during intermediate-term followup. World J Urol 2010;28:39-43.

10. Khoder WY, Zilinberg K, Waidelich R, Stief CG, Becker AJ, Pangratz $T$, et al. Ex vivo comparison of the tissue effects of six laser wavelengths for potential use in laser supported partial nephrectomy. J Biomed Opt 2012;17:068005.

11. Bui MH, Breda A, Gui D, Said J, Schulam P. Less smoke and minimal tissue carbonization using a thulium laser for laparoscopic partial nephrectomy without hilar clamping in a porcine model. J Endourol 2007;21:1107-11.

12. Khoder WY, Sroka R, Siegert S, Stief CG, Becker AJ. Outcome of laser-assisted laparoscopic partial nephrectomy without ischaemia for peripheral renal tumours. World J Urol 2012;30: 633-8.

13. Silkiss RZ. THC:YAG nasolacrimal duct recanalization. Ophthalmic Surg 1993;24:772-4.

14. Silkiss RZ, Axelrod RN, Iwach AG, Vassiliadis A, Hennings DR. Transcanalicular THC:YAG dacryocystorhinostomy. Ophthalmic Surg 1992;23:351-3.

15. Ludwig HC, Kruschat T, Knobloch T, Teichmann HO, Rostasy K, Rohde V. First experiences with a 2.0-microm near infrared laser system for neuroendoscopy. Neurosurg Rev 2007;30:195201; discussion 201.

16. Ayari-Khalfallah S, Fuchsmann C, Froehlich P. Thulium laser in airway diseases in children. Curr Opin Otolaryngol Head Neck Surg 2008;16:55-9.

17. Kay SL, Oz MC, Haber M, Blitzer A, Treat MR, Trokel SL. Soft tissue effects of the THC:YAG laser on canine vocal cords. Otolaryngol Head Neck Surg 1992;107:438-43.

18. Zeitels SM, Burns JA, Akst LM, Hillman RE, Broadhurst MS, Anderson RR. Office-based and microlaryngeal applications of a fiber-based thulium laser. Ann Otol Rhinol Laryngol 2006;115: $891-6$.

19. Zhizhina NA, Prokhonchukov AA, Ermolov VF, Pelkovskii Vlu. An automated computer system for the differential diagnosis and laser treatment of benign neoplasms and tumor-like masses in the oral cavity. Stomatologiia (Mosk) 1998;77:61-5.

20. Lowe D, van der Meulen J; National Prospective Tonsillectomy Audit. Tonsillectomy technique as a risk factor for postoperative haemorrhage. Lancet 2004;364:697-702.

21. Benninger $M$, Walner D. Coblation: improving outcomes for children following adenotonsillectomy. Clin Cornerstone 2007;9 Suppl 1:S13-23.

22. Grainger J, Saravanappa N. Local anaesthetic for posttonsillectomy pain: a systematic review and meta-analysis. Clin Otolaryngol 2008;33:411-9. 